\title{
AUTOMATIC MONITORING ALGORITHM OF POWER QUALITY VOLTAGE EVENTS
}

\author{
Mansour A. Mohamed \\ Electrical Engineering Department College of Engineering, Al-Jouf \\ University Skaka, Al-Jouf, B.O. Box2014, KSA \\ Email: mamohamed2004@yahoo.com
}

(Received January 18, 2009 Accepted February 16, 2009)

This paper presents an automatic monitoring algorithm of power quality $(P Q)$ voltage events. The proposed algorithm is based on using the recursive self-tuning least squares technique for the estimation of the magnitude, frequency and phase of the $P Q$ voltage signal components. The monitoring process is divided into two stages: detection stage and classification stage. The $P Q$ voltage events detected and classified are interruption, voltage sags, undervoltage, overvoltage, and voltage swells. Generated signals using parametric equations and simulated signals using electromagnetic transient program (EMTP-ATP) is used to test the validity and efficiency of the proposed practical method for automatic monitoring of $P Q$ voltage events. Event inception and end as well as duration are estimated in the detection phase. The results obtained show the very high accuracy of the proposed method.

KEYWORDS: Power Quality monitoring, Adaptive algorithm, Harmonics, voltage disturbances

\section{INTRODUCTION}

Nowadays power quality (PQ) has gained renewed interest and has become of great importance for the utilities and its customers due to dramatically increase of using nonlinear loads, power electronic equipment and sensitive computerized equipment as well as industrial drives. Such new loads are extremely affected by the quality of the supply voltage. Short duration power quality (SDPQ) voltage disturbances are the most frequent cause of a broad range of system equipment maloperation or even failure of sensitive control and protective equipment.

IEEE Std. 1159 [1] definition of the SDPQ voltage events is as follows: Interruption is a complete loss of voltage $(<0.1 \mathrm{pu})$ on one or more phase conductors for a time period between $3 \mathrm{~s}$ and $1 \mathrm{~min}$. Notch is sudden reduction of the normal power voltage waveform lasting less than 0.5 cycles. Overvoltage refers to a measured voltage having a value greater than the nominal voltage for a period of time greater than $1 \mathrm{~min}$. Typical values are from $1.1 \mathrm{pu}$ to $1.2 \mathrm{pu}$. Undervoltage refers to a measured voltage having a value less than the nominal voltage for a period of time greater than $1 \mathrm{~min}$. Typical values are from $0.8 \mathrm{pu}$ to $0.9 \mathrm{pu}$. Sag is a decrease to between $0.1 \mathrm{pu}$ and $0.9 \mathrm{pu}$ in rms voltage at power frequency for durations of 0.5 cycles to $1 \mathrm{~min}$. Typical values of sags are $0.1 \mathrm{pu}$ to $0.9 \mathrm{pu}$. Swell is an increase in rms voltage to $1.1 \mathrm{pu}$ and $1.8 \mathrm{pu}$ at power frequency. 
Robust and accurate automated techniques for detection and classification of the SDPQ voltage disturbances are of primary importance before the implementation of mitigating methods to enhance the quality of the power supplied. The advances in signal processing techniques and transform theories open up to new methodologies and techniques in automatic detection and classification of SDPQ disturbance voltage waveforms and a number of automated methodologies for monitoring and classifying SDPQ disturbances have been published over the last decade. The Fourier transform (FT) [2] has been used as features extraction technique. However, FT alone is not sufficient for capturing short-term transients due to the transient natures of most PQ and its constant bandwidth. Although the short-time Fourier transform (STFT) technique [3] was implemented to mitigate the problem associated with the FFT technique, it requires a significant amount of computation resources and its fixed window width imposes limitations for the analysis of low-frequency and high frequency nonstationary signals.

The wavelet transform (WT) [4] - [8] as an alternative to STFT is effectively used for providing an automated detection and classification of PQ disturbances especially nonstationary voltage and current waveforms. Wavelet transforms including continuous wavelet transform (CWT) and discrete wavelet transform can be effectively used for extracting the features of PQ disturbances; however its capability of delectation and classification PQ disturbances is degraded with noise and affected by the chosen basis wavelet. The S-transform [9] - a modified version of the wavelet transform or a variable window short-time Fourier transform is integrated with spline wavelet [10], fuzzy logic-based pattern recognition [11], rule-based decision tree [12], k-nearest neighbor (KNN) technique [13], or probabilistic neural network [13] to detect and classify PQ events. The KNN wavelet transform classifier has been utilized for classifying nine types of PQ events [13]. 500 generated data points represent each type. Wavelet multiresolution analysis (MRA), S-transform (ST), Clarke transformation (CT), and Discrete Hilbert transform (DHT) are used for extracting seven features. The classification accuracy of each type of events is from 50\% to $100 \%$ for KNN-CT and from $52.8 \%$ to $100 \%$ for KNN-HT.

Mishra [14] has classified eleven simulated classes of PQ events by using PNN and compared with a feedforward multiplayer (FFML) neural network and learning vector quantization (LVQ) neural network. S-transform has been used for extracting four features based on the standard deviation and energy of the transformed signal. The overall classification accuracy of LVQ and FFML degrades with increasing the number of data points whereas of PNN the overall accuracy increases to $98.64 \%$ for 50 data point of each event. On the other hand, the overall accuracy of PNN under noisy environment degrades to $93.2 \%$.

Recently, support vector machine (SVM) neural network and radial basis function (RBF) networks are proposed [15]-[16] for classifying six PQ events. Clark transform is used for extracting the features of three-phase signals.

Unlike these efforts, the proposed is based of tracking the amplitude, frequency and phase of the power frequency component and the higher order components of the SDPQ voltage signals. The amplitudes of the components are used to estimate the true instantaneous rms of the SDPQ voltage signal. The fundamental of adaptive self-tuning least squares is described in Section 2. Signal modeling and 
detection and classification scheme are introduced in Section 3. The simulation results are presented in Section 4.

\section{ADAPTIVE MONITORING ALGORITHM}

The voltage signal measured at the point of common coupling of a distribution system contains a significant power in the low order harmonics with varying amplitude depending on the load conditions and the degree of disturbances occurance The voltage signal digitized at the point of the measurement can be modeled as:

$$
\begin{aligned}
v(t)=V_{o} e^{-t / \tau}+\sum_{k=1}^{M} V_{k} \sin \left(k \omega t+\varphi_{k}\right)+\zeta(t) \\
=V_{o} e^{-t / \tau}+\sum_{k=1}^{M} V_{p k} \sin (k \omega t)+\sum_{k=1}^{M} V_{q k} \cos (k \omega t) .
\end{aligned}
$$

The decaying dc component magnitude is $V_{o}$ at $t=0$ and $\tau$ is the time constant. $M$ is the highest order of the harmonic presented in the signal. $\omega$ is the fundamental angular velocity. $V_{k}$ is the magnitude of the $k t h$ harmonic. $V_{p k}$ and $V_{q k}$ are the orthogonal components of the $k t h$ harmonics, and $\varphi_{k}$ is the phase angle of the $k t h$ harmonic. In order to avoid nonlinear estimation, the first two terms of Taylor series expansion has been applied to the decaying dc component. Due to the nonlinearity in the signal frequency, $\sin (k \omega t)$ and $\cos (k \omega t)$ is also expanded in the neighborhood of an expected value of $\omega=\omega_{o}$. The linearized form of the voltage waveform can be expressed by:

$$
\begin{gathered}
v(t)=V_{o}-V_{o} t / \tau+\sum_{k=1}^{M}\left(V_{p k} \sin \left(k \omega_{o} t\right)+V_{p k} \Delta \omega k t \cos \left(k \omega_{o} t\right)\right) \\
+\sum_{k=1}^{M}\left(V_{q k} \cos \left(k \omega_{o} t\right)-V_{q k} \Delta \omega k t \sin \left(k \omega_{o} t\right)\right) .
\end{gathered}
$$

The model order, determined by $M$, is $4 M+2$. Now (2) can be written in matrix form

$$
v(t)=W^{T}(t) X(t)+\zeta(t)
$$

where

$$
W=\left[\begin{array}{l}
w_{o} \\
w_{1} \\
w_{1+k} \\
w_{1+k+M} \\
w_{1+k+2 M} \\
w_{1+k+3 M}
\end{array}\right]=\left[\begin{array}{l}
V_{o} \\
V_{o} / \tau \\
V_{p k} \\
V_{q k} \\
V_{p k} \Delta \omega \\
V_{q k} \Delta \omega
\end{array}\right] \quad \text { and } \quad \mathbf{X}=\left[\begin{array}{l}
x_{o} \\
x_{1} \\
x_{1+k} \\
x_{1+k+M} \\
x_{1+k+2 M} \\
x_{1+k+3 M}
\end{array}\right]=\left[\begin{array}{l}
1 \\
-t \\
\sin \left(k \omega_{o} t\right) \\
\cos \left(k \omega_{o} t\right) \\
k t \cos \left(k \omega_{o} t\right) \\
-k t \sin \left(k \omega_{o} t\right)
\end{array}\right] .
$$

The present error $\zeta(n)$ at the $n t h$ iteration is defined to be the difference between the voltage measured sample $v(n)$ and the linear output value $\hat{v}(n)$. Having the signal digitized with a sampling frequency $f_{s}=1 / T_{S} \mathrm{~Hz}$, the estimated linear output 
value of the digitized voltage waveform can be estimated at each instant of time $t_{n}=$ $(n-1) T_{s}$ by the following form:

$$
\hat{v}(n)=\mathbf{W}^{T}(n) \mathbf{X}(n)=\sum_{k=0}^{4 M+1} W_{k}(n) x_{k}(n)
$$

where $\hat{v}(n)$ is the estimated linear output at the $n$th sample of the voltage waveform. $\mathbf{W}^{T}$ is the transpose of the weight vector $\mathbf{W}$, with the elements defined by (4) and $\mathbf{X}$ is a $(4 M+1)$ coefficient vector, with the elements defined by (4). Having the weight vector $\mathbf{W}$, the magnitude, phase and frequency of the measured voltage signal can be obtained as follows:

$$
\begin{aligned}
& V_{o}=w_{o}, \tau=w_{o} / w_{1}, \\
& V_{k}=\sqrt{w^{2}{ }_{1+k}+w^{2}{ }_{1+k+M}}, \\
& \varphi_{k}=\tan ^{-1}\left(\frac{w_{1+k+M}}{w_{1+k}}\right), \\
& \Delta \omega=\frac{w_{1+k+2 M}}{w_{1+k}}, \\
& \omega=\omega_{o}+\alpha \Delta \omega .
\end{aligned}
$$

The tuning parameter $\alpha$ is used in the algorithm to accelerate or decelerate the tuning process of the algorithm. This tuning factor is adaptively estimated based on the sum of the absolute values of the residual errors. The tuning parameter can be expressed in the following form [17]:

$$
\alpha=\alpha_{o}+\left(\alpha_{1}-\alpha_{o}\right)\left(1-e^{-R / R_{o}}\right)
$$

where $\alpha_{o}, \alpha_{l}$, and $R_{o}$ are the tuning parameters. The weight vector, $\boldsymbol{W}$, is updated by using the adaptive RLS rule,

$$
\mathbf{W}(n+1)=\mathbf{W}(n)+\mu \xi(n) \mathbf{X}(n)
$$

where $\mu$ is an acceleration factor. Therefore, the error is reduced by $\mu$ as the weight vector is changed.

\section{SIGNAL MODELING}

To test the performance of the proposed detection and classification technique, five SDPQ voltage events are generated by parametric equations and EMTP-ATP simulation program [18]. The generated signals using parametric equations or signals originated from ATP-EMTP are sampled at 256 sample/cycle for power frequency of $50 \mathrm{~Hz}$ with varying window size for detection and classification. For all generated events the disturbances start after the first cycle. The amplitude and duration variations of the generated SDPQ events are listed in Table I.

The three-phase distribution network as shown in Fig. 1 is modeled in EMTPATP to obtain different SDPQ voltage events. All voltage sags, undervoltage, and 
interruption generated are due to faults. Four types of faults are simulated which are: single-line-to-ground fault (SLGF), line-to-line fault (LLF), double-line-to-ground fault (DLGF), and three-phase-to-ground fault (3PGF). The fault type, location, and resistance are randomly selected as well as the initial time of the fault. Load rejection and capacitor switching are simulated for the purpose of obtaining voltage swells and overvoltage data.

TABLE I

TYPICAL AMPLITUDES AND DURATIONS OF SHORT DURATION POWER QUALITY EVENTS

\begin{tabular}{c|c|c}
\hline \hline Event & Amplitude & Duration \\
\hline \hline Sags & $0.1 \mathrm{pu}$ to $0.9 \mathrm{pu}$ & $\mathbf{0 . 5}$ cycles to $1 \mathrm{~min}$ \\
\hline \multirow{3}{*}{ Swells } & $1.1 \mathrm{pu}$ to $1.2 \mathrm{pu}$ & $\mathbf{0 . 5}$ cycles to $1 \mathrm{~min}$ \\
\cline { 2 - 3 } & $1.1 \mathrm{pu}$ to $1.4 \mathrm{pu}$ & $\mathbf{0 . 5}$ cycles to $3 \mathrm{~s}$ \\
\cline { 2 - 3 } & $1.1 \mathrm{pu}$ to 1.8 & 0.5 cycles to $0.6 \mathrm{~s}$ \\
\hline Overvoltages & $1.1 \mathrm{pu}$ to $1.2 \mathrm{pu}$ & $>1 \mathrm{~min}$ \\
\hline Undervoltages & $0.8 \mathrm{pu}$ to $0.9 \mathrm{pu}$ & $>1 \mathrm{~min}$ \\
\hline Interruption & $<0.1 \mathrm{pu}$ & $3 \mathrm{~s}$ to $1 \mathrm{~min}$ \\
\hline \hline
\end{tabular}

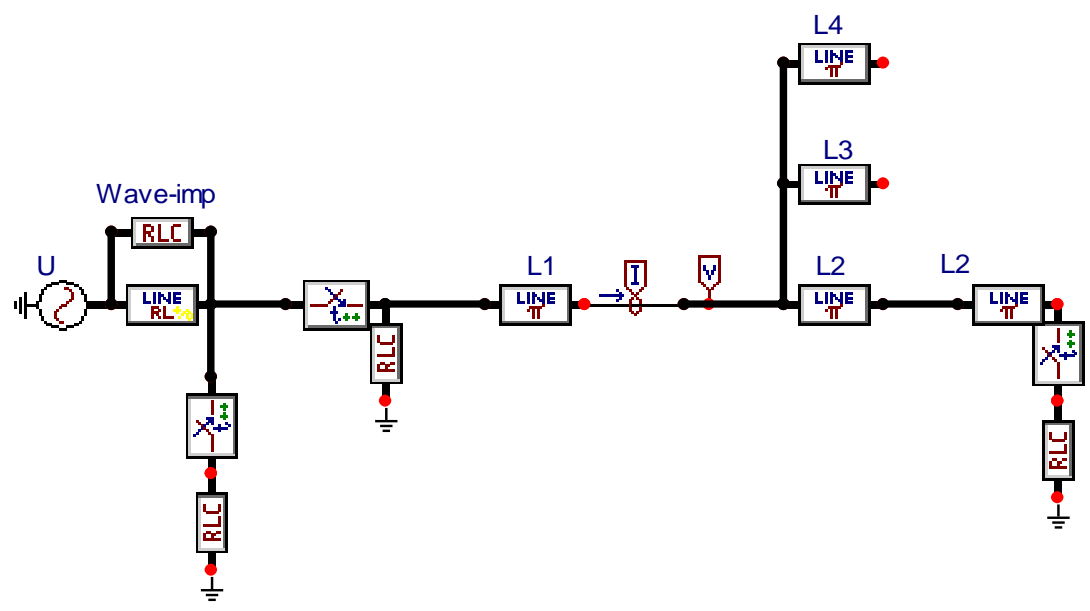

Fig. 1: ATP Draw connection circuit.

\section{Simulation Results}

\subsection{Detection stage}

A sample of the studied cases is presented to illustrate the effectiveness of the method to detect SDPQ voltage events. A double-line-to-ground fault through a $0.5 \Omega$ fault resistance occurred at the receiving end of the transmission line (L2) in the system shown in Fig. 1 at $0.6055 \mathrm{~s}$ and cleared at $0.8066 \mathrm{~s}$. The faulted phases " $\mathrm{a}$ " and ' $\mathrm{B}$ ' experience voltage sag, while the unfaulted " $C$ " phase experience a voltage swell. Fig. 2 shows the normalized voltage signals of phase "A" at the end of L1 and the estimated 
voltage amplitude and the estimated frequency variation. The algorithm detects and characterizes the signal as sag at $0.608 \mathrm{~s}$ in $2.5 \mathrm{~ms}$. The event is confirmed sag at $0.694 \mathrm{~s}$. the end of the event is detected at $0.838 \mathrm{~s}$.

Figure 3 shows the normalized voltage signals of phase " $\mathrm{B}$ " at the end of L1 and the estimated voltage amplitude and the estimated frequency variation. The algorithm detects and characterizes the signal as interruption at $0.673 \mathrm{~s}$ in $67.5 \mathrm{~ms}$, which is the confirmed time for this event. The end of the event is detected at $0.762 \mathrm{~s}$. The event status is changed to sag at that time and event ends at $0.848 \mathrm{~s}$.

Figure 4 shows the normalized voltage signals of phase " $\mathrm{C}$ " at the end of L1 and the estimated voltage amplitude and the estimated frequency variation. The algorithm detects and characterizes the signal as swell at $0.6068 \mathrm{~s}$ in $1.3 \mathrm{~ms}$ and confirmed swell at $0.6141 \mathrm{~s}$. The event is characterized to be medium swell at 0.624 . The end of the medium swell event is detected at $0.7248 \mathrm{~s}$. The event ends at $0.863 \mathrm{~s}$.
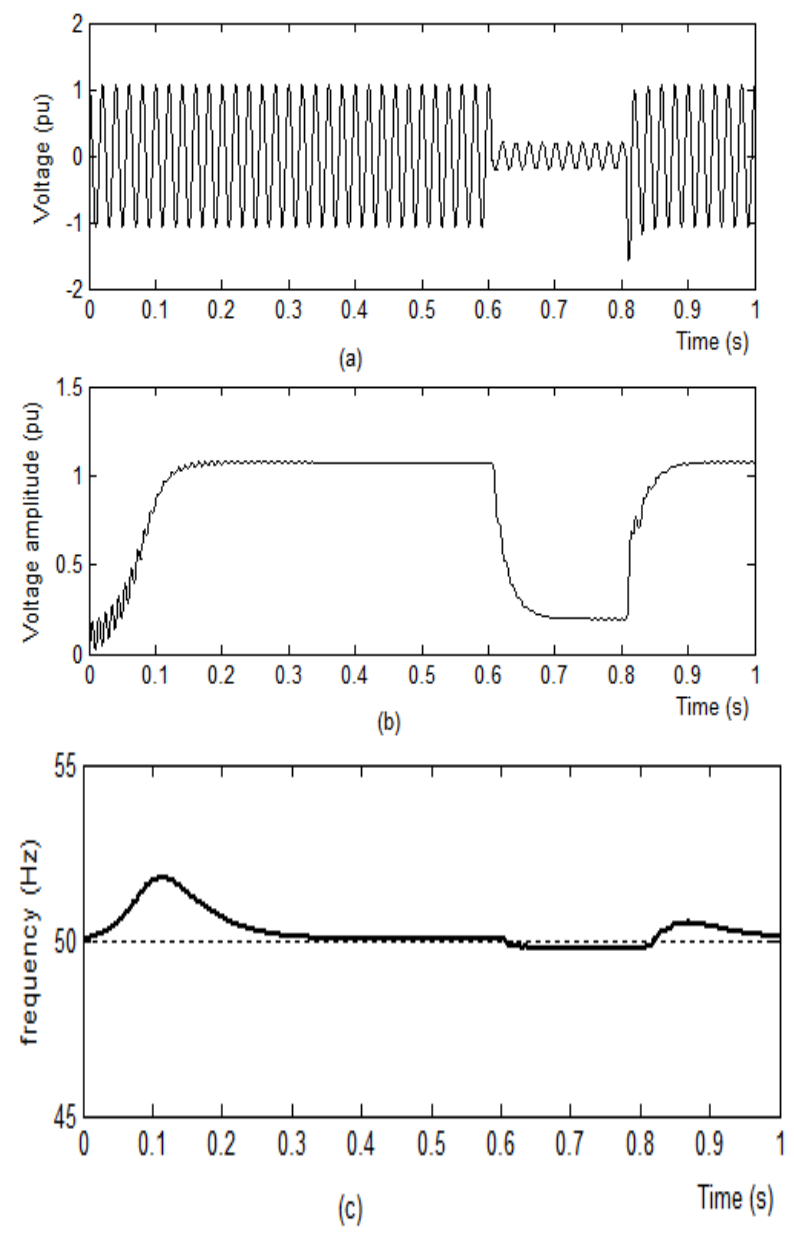

Fig. 2: Normalized voltage sag. (a) Voltage waveform of phase "A due to DLGF. (b) The estimated voltage amplitude using adaptive STLS. (c) Frequency variations. 

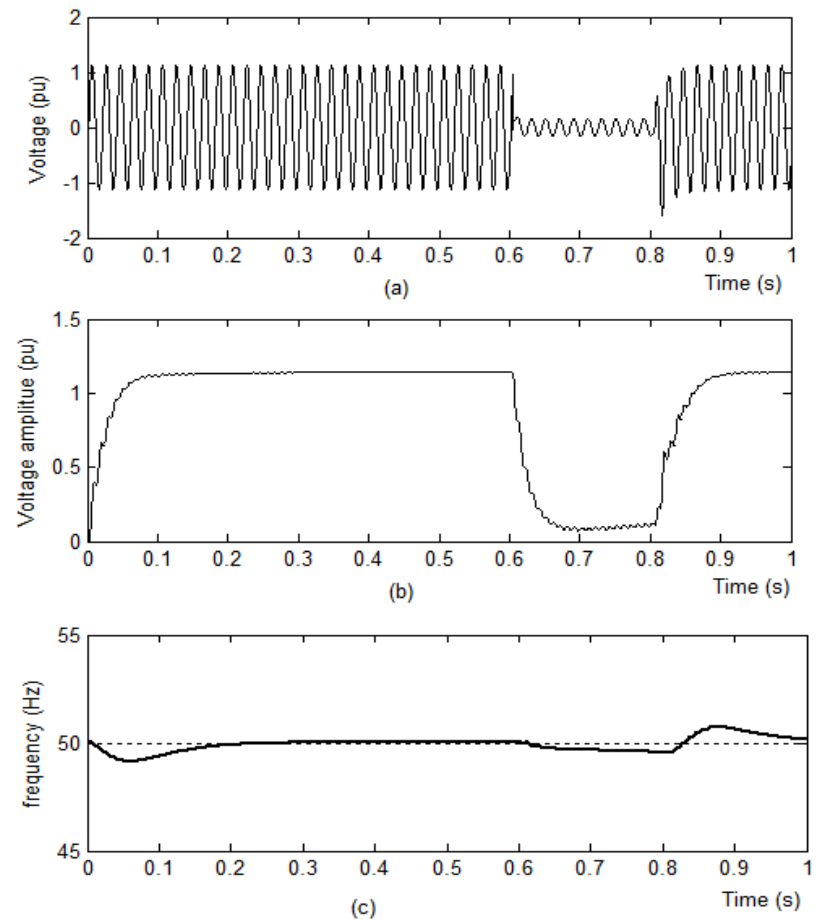

Fig. 3: Normalized voltage interruption. (a) Voltage waveform of phase "B" due to DLGF. (b) The estimated voltage amplitude using adaptive STLS. (c) Frequency variations.
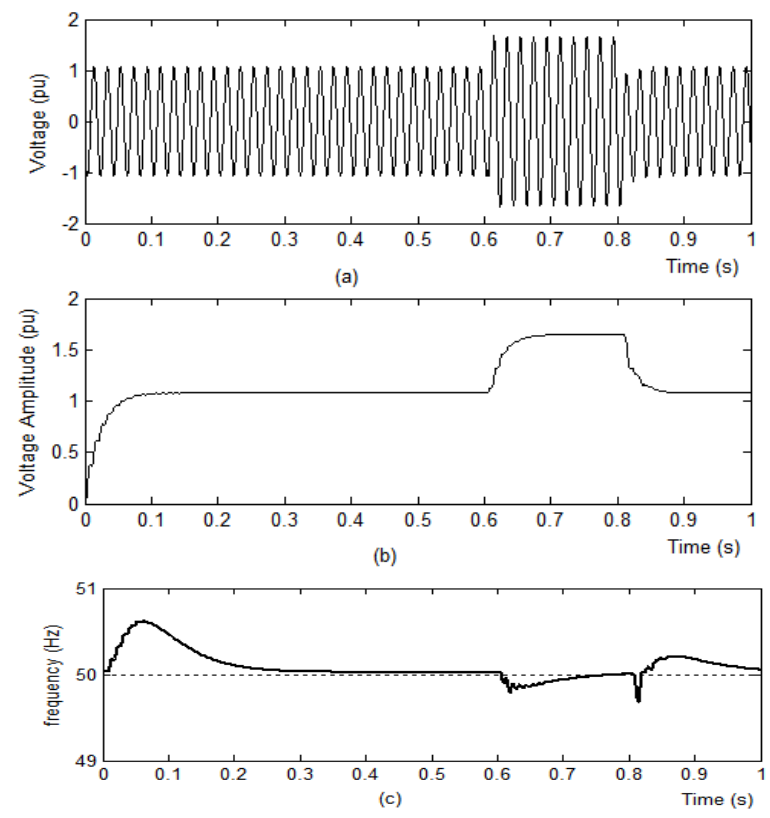

Fig. 4: Normalized voltage swell. (a) Voltage waveform of phase "C" due to DLGF. (b) The estimated voltage amplitude using adaptive STLS. (c) Frequency variations. 


\subsection{Classification stage}

The features of the automatic classification process of the five SDPQ voltage disturbances are based only on the amplitude variations and the duration of these events, which are specified in Section III. The classification results of a total of 500 generated cases using parametric equations are shown in Table II with 100 cases for each type of the five-SDPQ events. The diagonal elements represent correctly classified SDPQ voltage events. Off-diagonal elements represent the misclassification. The overall accuracy of correct classification is the ratio of correctly classified events to that of the total number of events. Considering only 25 cases for each type, the overall classification accuracy obtained is $98.4 \%$. For higher number of cases, 100 case for each type of a total of 500 cases the overall accuracy degrades to $97 \%$ as illustrated in Table II.

TABLE II

Classification Results of the Generated Events

\begin{tabular}{c|c|c|c|c}
\hline \multirow{2}{*}{ Event } & \multicolumn{4}{|c}{ Number of analyzed cases for each type } \\
\cline { 2 - 5 } & 25 & 50 & 75 & 100 \\
\hline Sags & 25 & 50 & 74 & 98 \\
\hline Swells & 25 & 49 & 74 & 99 \\
\hline Interruption & 24 & 49 & 72 & 93 \\
\hline Overvoltage & 25 & 50 & 75 & 100 \\
\hline Undervoltage & 24 & 48 & 71 & 95 \\
\hline Overall accuracy & $98.4 \%$ & $98.4 \%$ & $97.6 \%$ & $97 \%$ \\
\hline
\end{tabular}

Automatic classification of generated SDPQ signals given by parametric equations delivered satisfactory results. However, the influence of noise and fault resistance required further research. A model of a three-phase distributed system is built in EMTP-ATP environment. The model of the distribution system is shown in Fig. 2. The system is working at $24 \mathrm{kV}, 50 \mathrm{~Hz}$. The distributed lines L1, L2, and L3 are typical overhead lines with lengths of $3 \mathrm{~km}, 3 \mathrm{~km}$, and $5 \mathrm{~km}$, respectively. The short circuit occurs at the end of the line L1.

During the investigations, different cases for every fault type and load shedding or capacitor injection were simulated, to cover a wide range of possible configurations in real power systems. The influence of the duration time of a fault and the length of the faulted line on the classification of SDPQ were the area of interest. Different short-circuit times were applied. The duration of a fault varied between 0.011.1s. 72 cases for each type of SDPQ events with a total of 360 cases are extracted for the classification purposes. The classifier should recognize SDPQ events independently from the amplitude and duration.

The classification results of the simulated events using EMTP_ATP program listed in Table III shows that the accuracy is $98.9 \%$ for 18 cases of each type. The classification results of the combined generated and simulated cases are tabulated in Table IV. The classification accuracy of the algorithm for each type of SDPQ event is shown in Table V. The overall classification accuracy is about $96.9 \%$. 
TABLE III

Detection Results of the Simulated Events Using EMTP

\begin{tabular}{c|c|c|c|c}
\hline \multirow{2}{*}{ Event } & \multicolumn{4}{|c}{ Number of analyzed cases for each type } \\
\cline { 2 - 5 } & 18 & 36 & 54 & 72 \\
\hline Sags & 18 & 34 & 52 & 69 \\
\hline Swells & 18 & 36 & 54 & 72 \\
\hline Interruption & 17 & 33 & 50 & 67 \\
\hline Overvoltage & 18 & 35 & 53 & 70 \\
\hline Undervoltage & 18 & 35 & 51 & 71 \\
\hline Accuracy & $98.9 \%$ & $96.1 \%$ & $96.3 \%$ & $96.9 \%$ \\
\hline
\end{tabular}

TABLE IV

Classification Results of the Generated and Simulated Events

\begin{tabular}{c|c|c|c|c|c}
\hline & Sags & Swells & Interrup. & Over-V & Under-V \\
\hline Sags & 167 & 0 & 3 & 1 & 1 \\
\hline Swells & 0 & 170 & 0 & 2 & 0 \\
\hline Interrup. & 8 & 0 & 160 & 0 & 4 \\
\hline Over-V & 0 & 2 & 0 & 170 & 0 \\
\hline Under-V & 6 & 0 & 0 & 0 & 166 \\
\hline Accuracy & $97.1 \%$ & $98.8 \%$ & $93 \%$ & $98.8 \%$ & $96.5 \%$ \\
\hline
\end{tabular}

TABLE V

CLASSIFICATION ACCURACY

\begin{tabular}{c|c|c|c|c|c}
\hline Accuracy & Sags & Swells & Interrup. & Over-V & Under-V \\
\hline Generated & 98 & 99 & 93 & 100 & 95 \\
\hline Simulated & 95.8 & 100 & 93.1 & 97.2 & 98.6 \\
\hline Overall & 97.1 & 98.8 & 93 & 98.8 & 96.5 \\
\hline
\end{tabular}

\section{CONCLUSION}

This paper attempts to propose a new method for detection and classification of five common types of SDPQ voltage disturbances. The proposed method is based on adaptive STLS algorithm for tracking the voltage signal amplitude, frequency and phase. The amplitude and duration estimated are used as features for detecting and classifying the SDPQ voltage event. The results from generated and simulated cases during the detection process show the ability of the algorithm to detect SDPQ voltage disturbance within a quarter cycle. It is observed that the proposed method correctly classifies the SDPQ voltage disturbances with high accuracy. The classification result shows that the overall accuracy is greater than $96.5 \%$.

\section{REFERENCES}

[1] IEEE Recommended Practice for monitoring Electric Power Quality, IEEE1159std. 1995.

[2] S. Santoso, E. J. Powers, W. M. Grady, and P. Hofmann, "Power quality assessment via wavelet transform analysis," IEEE Trans. Power Delivery, vol. 11, pp. 924-930, apr. 1996. 
[3] Y. H. Gu and M. H. Bollen," Time-frequency and time-scale domain analysis of voltage disturbances," IEEE Trans. Power Delivery, vol. 15, no. 4, pp. 1279-1284, Oct. 2000.

[4] A. M. Gouda, M. M. A. Salama, M. R. Sultan, and A. y. Chikhani, "Power quality detection and classification using wavelet multiresolution signal decomposition," IEEE Trans. Power Delivery, vol. 14, pp. 1469-1476, Oct. 1999.

[5] O. Poisson, P. Rioual, and M. meunier, "Detection and measurement of power quality disturbances using wavelet transform," IEEE Trans. Power Delivery, vol. 15, no. 3, pp. 1039-1044, Jul. 2000.

[6] S. Santoso, W. M. Grady, E. J. Powers, J. Lamoree, and S. C. Bhatt, "Characterization of distribution power quality events with Fourier and wavelet transforms," IEEE Trans. Power Delivery, vol. 15, no. 1, pp. 247-254, Jan. 2000.

[7] T. K. Abdel-Galil, M. Kamel, A. M. Youssef, E. F. El-Saadany, and M. M. A. Salama, "Power quality disturbance classification using the inductive inference approach," IEEE Trans. Power Delivery, vol. 19, no. 4, pp. 1812-1818, Oct. 2004.

[8] H. He, and J. A. Starzyk, "A self-organization learning array system for power quality classification based on wavelet transform," IEEE Trans. Power Delivery, vol. 21, no. 1, pp. 286-295, Jan. 2006.

[9] R. G. Stockwell, L. Mansinha, and R. P. Lowe, "Localization of the complex spectrum: The S-transform,” IEEE Trans. Signal process., vol. 44, no. 4, pp. 9981001, Apr. 1996.

[10] P. K. Dash, B. K. Panigrahi, D. K. Sahoo, and G. Panda, "Power quality disturbance data compression, detection, and classification using integrated spline and s-transform," IEEE Trans. Power Delivery, vol. 18, no. 2, pp. 595-600, Apr. 2003.

[11] M. V. Chilukuri, and P. K. Dash, "Multiresolution s-transform-based fuzzy recognition system for power quality events," IEEE Trans. Power Delivery, vol. 19, no. 1, pp. 323-330, Jan. 2004.

[12] F. Zhao, and R. Yang, "Power-quality disturbance recognition using stransform," IEEE Trans. Power Delivery, vol. 22, no. 2, pp. 944-950, Apr. 2007.

[13] A. M. Gargoon, N. Ertugrul, and W. L. Soong, "Investigation of effective automatic recognition systems of power-quality events," IEEE Trans. Power Delivery, vol. 22, no. 4, pp. 2319-2326, Oct. 2007.

[14] S. Mishra, C. N. Bhende, and B. K. Panigrarahi, "Detection and classification of power quality disturbances using s-transform and probabilistic neural network," IEEE Trans. Power Delivery, vol. 23, no. 1, pp. 280-287, Jan. 2008.

[15] P. Janik, and T. Lobos, "Automated classification of power-quality disturbances using SVM and RBF networks," IEEE Trans. Power Delivery, vol. 21, no. 3, pp. 1663-1669, Jul. 2006.

[16] P. G. V. Axelberg, I. Y. Gu, and M. H. J. Bollen, "Support vector machine for classification of voltage disturbances," IEEE Trans. Power Delivery, vol. 22, no. 3, pp. 1297-1303, Jul. 2007.

[17] V. Terzija, and V. Stanojevic, "STLS Algorithm for power-quality indices estimation," IEEE Trans. Power Delivery, vol. 23, no. 2, pp. 544-552, Apr. 2008.

[18] H. W. Dommel, Electromagnetic Transients Program. Reference Manual (EMTP Theory Book), Bonneville Power Administration, Portland, 1986. 


\section{خوارزمية مراقبة آلية لجودة قدرة أحداث الجهر}

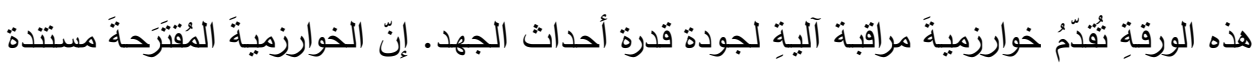
على استعمال تقنيةِ ضبط ذاتيةِ لأقل مربع الأخطاء التكراريةِ لتقديرِ المقدارِ وترددِ وطور مكوّناتِ الجهد.

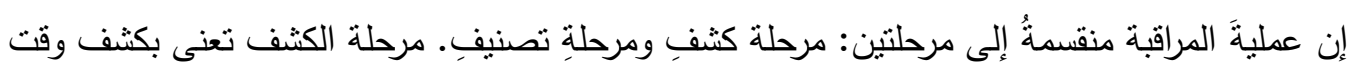

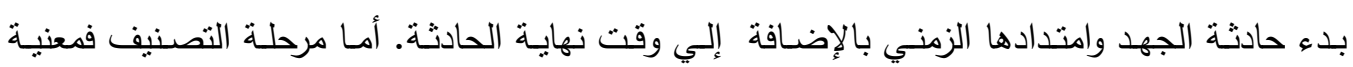

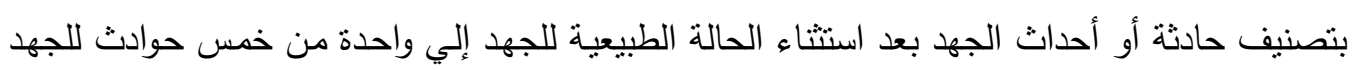
وهي : جهد ترخيم، جهد منتفخ، جهد مرتفع، جهد منخفض و جهد مقطوع هناك نوعان من البيانات

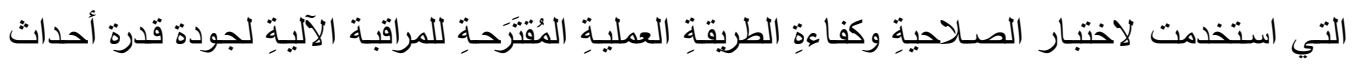
الجهد. النوع الأول من البيانات استخلصت من معادلات آنية للخمس حوادث سابقة الذكر ـ أما النوع الثناني مـن البيانـات فـتم استخلاصـهـ مـن خـلال عمـل محساكي لمغنــي كهربـي باسـتخدام برنـامج (Electromagnetic Transient Program) للخوارزمية المقترحة في كثف وتصنيف جودة قدرة أحداث الجهد. 